\title{
Influx of diverse, drug resistant and transmissible Plasmodium falciparum into a malaria-free setting in Qatar
}

Abir Al-Rumhi', Zainab Al-Hashami', Salama Al-Hamidhi', Amal Gadalla', Raeece Naeem², Lisa Ranford-Cartwright ${ }^{3}$, Arnab Pain ${ }^{2,4,5}$, Ali A. Sultan ${ }^{6}$ and Hamza A. Babiker ${ }^{1,7^{*}}$

\begin{abstract}
Background: Successful control programs have impeded local malaria transmission in almost all Gulf Cooperation Council (GCC) countries: Qatar, Bahrain, Kuwait, Oman, the United Arab Emirates (UAE) and Saudi Arabia. Nevertheless, a prodigious influx of imported malaria via migrant workers sustains the threat of local transmission. Here we examine the origin of imported malaria in Qatar, assess genetic diversity and the prevalence of drug resistance genes in imported Plasmodium falciparum, and finally, address the potential for the reintroduction of local transmission.
\end{abstract}

Methods: This study examined imported malaria cases reported in Qatar, between 2013 and 2016. We focused on P. falciparum infections and estimated both total parasite and gametocyte density, using GPCR and qRT-PCR, respectively. We also examined ten neutral microsatellites and four genes associated with drug resistance, Pfmrp1, Pfcrt, Pfmdr1, and Pfkelch13, to assess the genetic diversity of imported P. falciparum strains, and the potential for propagating drug resistance genotypes respectively.

Results: The majority of imported malaria cases were $P$. vivax, while $P$. falciparum and mixed species infections ( $P$. falciparum / P. vivax) were less frequent. The primary origin of $P$. vivax infection was the Indian subcontinent, while $P$. falciparum was mostly presented by African expatriates. Imported $P$. falciparum strains were highly diverse, carrying multiple genotypes, and infections also presented with early- and late-stage gametocytes. We observed a high prevalence of mutations implicated in drug resistance among these strains, including novel SNPs in Pfkelch13.

Conclusions: The influx of genetically diverse $P$. falciparum, with multiple drug resistance markers and a high capacity for gametocyte production, represents a threat for the reestablishment of drug-resistant malaria into GCC countries. This scenario highlights the impact of mass international migration on the reintroduction of malaria to areas with absent or limited local transmission.

Keywords: Gulf cooperation council (GCC) countries, Imported malaria, Malaria elimination, P. falciparum, Gametocytes, Qatar

\footnotetext{
* Correspondence: Hbabiker@squ.edu.om

'Department of Biochemistry, College of Medicine and Health Sciences, Sultan Qaboos University, Muscat, Oman

Institute of Immunology and Infection Research, School of Biological Sciences, University of Edinburgh, Edinburgh, UK

Full list of author information is available at the end of the article
}

(c) The Author(s). 2020 Open Access This article is licensed under a Creative Commons Attribution 4.0 International License, which permits use, sharing, adaptation, distribution and reproduction in any medium or format, as long as you give appropriate credit to the original author(s) and the source, provide a link to the Creative Commons licence, and indicate if changes were made. The images or other third party material in this article are included in the article's Creative Commons licence, unless indicated otherwise in a credit line to the material. If material is not included in the article's Creative Commons licence and your intended use is not permitted by statutory regulation or exceeds the permitted use, you will need to obtain permission directly from the copyright holder. To view a copy of this licence, visit http://creativecommons.org/licenses/by/4.0/ The Creative Commons Public Domain Dedication waiver (http://creativecommons.org/publicdomain/zero/1.0/) applies to the data made available in this article, unless otherwise stated in a credit line to the data. 


\section{Background}

The Gulf Cooperation Council (GCC) countries have been successful in malaria control. The increased investments in control efforts beginning in the 1950s, are largely responsible for the interruption of local transmission, and ultimately led to malaria-free status in four of the six GCC countries. In Saudi Arabia, limited foci of indigenous malaria still exist [1, 2], and in Oman sporadic outbreaks still occur periodically [3]. These successes have encouraged health ministries in GCC countries to shift policy toward a malaria-free Arabian Peninsula [4] and to focus on preventing reintroduction via sustainable vector control policy, improved surveillance, and prompt case management [5].

Qatar has been free from local malaria transmission since the 1970s [6], with no reports of autochthonous malaria [7]. Despite this, the influx of migrant workers from malaria-endemic countries of the Indian subcontinent and sub-Saharan Africa has sustained a relatively high number of imported cases, representing a major threat for the restoration of local transmission patterns. Migrant workers constitute the majority of residents in most GCC countries, reaching $>80 \%$ of the populace in Qatar [8]. Over the past two decades there has been an increase in the flow of migrant workers to Qatar in particular. This migratory trend has been associated with a positive trend in reported cases of imported malaria [7, $9,10]$. In addition to an increase in imported malaria, the receptivity and risk of malaria reintroduction is evident by the continued presence of the mosquito vectors Anopheles stephensi and An. multicolor [11].

Similar risk factors exist in other GCC countries, with relatively high percentages of expatriates from malarious areas. Many migrant freelance labourers from the Indian subcontinent are subject to crowded, sub-standard living conditions, work in stressful jobs in construction and agriculture that undermine immune health, and live in close proximity to irrigation sites or water tanks, thus having an increased exposure to mosquito vectors [3]. In Oman, there have been malaria outbreaks, presumably seeded from imported cases, as a consequence of these conditions, with infected individuals not identified and treated early enough to prevent transmission to the indigenous Anopheles population [3].

The chronic nature of asymptomatic malaria infection, common in adults from malaria-endemic countries, in conjunction with population mobility, creates a threat to effective, long-term malaria elimination [12]. Imported asymptomatic infection often carries drug-resistant strains of the Plasmodium parasite $[9,13]$, posing an imminent threat to receptive regions where local transmission has been eliminated or targeted for elimination [14]. An improved understanding of transmission patterns, extending to parasite genetic diversity, and the prevalence of drug-resistant strains of imported malaria aids the deployment of effective cross-border mitigation measures.

The present study examines the source of imported malaria to the transmission-free country of Qatar, and assesses the genetic diversity, prevalence of drug resistance mutations, and ability of $P$. falciparum to produce gametocytes and thus be transmitted to mosquito vectors. Such knowledge would allow control programs to develop targeted policies to reduce circulating parasites, define the source of outbreaks and limit the risk of reintroduction of malaria.

\section{Methods}

\section{Subjects}

A total of 583 patients reporting to either Hamad General Hospital or Al-Khor Hospital, two main centers of Hamad Medical Corporation (HMC), Doha, Qatar, were tested for malaria between January 2013 and October 2016. All malaria cases were diagnosed using microscopic examination of Giemsa-stained thick (100 fields) and thin blood (1000 RBC) films. A total of 448 (76.8\%) of subjects tested positive for malaria, and based on disease history questionnaires, the origin of infection in all patients originated in endemic regions outside of Qatar [15]. Genomic DNA from capillary blood was isolated and purified using a QIAamp DNA bloodmini kit, following the manufacturer's instructions (Qiagen, CA, USA). Plasmodium species identification was confirmed using species-specific PCR, as described elsewhere [16]. Quantitation of P. falciparum was carried out by qPCR of $18 s$ rRNA [17]. Demographic information on each subject was ascertained using a survey, including variables such as age, sex, nationality, travel history, and previous malaria diagnoses/treatments. Patients who tested positive were provided with appropriate antimalarial treatment, according to the current, standard guidelines at HMC [11].

\section{Microsatellite genotyping and multiplicity of infection (MOI)}

A panel of ten unlinked polymorphic microsatellites of $P$. falciparum were genotyped as described by Anderson and colleagues [17, 18]. PCR products were subjected to capillary electrophoresis using an ABI 3130XL Genetic Analyzer (Applied Biosystems, UK). Gene Mapper software version 4 (Applied Biosystems, UK) was used to score allele size and quantify electropherogram peak heights for samples containing multiple alleles per locus. Multiple alleles per locus were scored if an 
electrophoretic peak corresponding to a minor allele was $>32 \%$ of the height of the predominant allele [17].

\section{Detection and quantitation of early- and late-stage $P$. falciparum gametocytes}

Quantitative RT-PCR (qRT-PCR) was employed to detect and quantify mRNA from the early gametocyte-specific gene, Pfpeg4 [19], and the late gametocyte-specific gene, pfs 25 [20]. Total RNA was first isolated from $100 \mu \mathrm{L}$ of capillary blood (collected via finger stick) using an SV Total RNA Isolation System (Promega, U.K.). Quantitative reverse transcription and subsequent amplification (qRTPCR) of cDNA was carried out using a High Capacity cDNA Reverse Transcription Kit (Thermo Fisher, U.K.). RT-PCR conditions and primers were those previously described by Hemson et al. and Schneider et al. [21, 22].

\section{Amplicon sequencing for the characterization of $P$. falciparum drug resistance loci}

SNPs in four $P$. falciparum genes implicated in resistance to several antimalarial drugs, Pfmrp1 (PF3D7_0112200), Pfcrt (PF3D7_0709000), Pfmdr1 (PF3D7_0523000), and PfK13 (PF3D7_1343700), were typed according to the methodology of Rao et al. [23]. Multiplex PCR was combined with custom-designed sequence analysis using the Illumina ${ }^{\circ}$ Miseq sequencing protocol (for the highthroughput SNP profiling of drug resistance genes) [23]. Seventy $P$. falciparum isolates were examined together with two controls, laboratory $P$. falciparum clones 3D7 and Dd2, with known alleles of the examined genes and phenotypic responses to antimalarials [23]. The PfK13 and Pfcrt genes were each amplified as single fragments, while the longer Pfmdr1 and Pfmrplgenes were each amplified as two fragments. PCR was carried out using the following conditions, in a total volume of $25 \mu \mathrm{l}: 1 \mu \mathrm{l}$ $(10 \mathrm{pmol})$ of primers, $0.4 \mu \mathrm{l}$ of dNTPs $(200 \mu \mathrm{mol} / \mathrm{L})$, $4 \mu \mathrm{l}$ of Phusion HF buffer (5x) and $1 \mathrm{U}$ of Phusion high-fidelity polymerase enzyme. The cycling profile for all loci was as follows: $98^{\circ} \mathrm{C} / 30 \mathrm{~s}$, followed by 30 cycles of $\left(98^{\circ} \mathrm{C} / 10 \mathrm{~s}, 64{ }^{\circ} \mathrm{C} / 4 \mathrm{~min}\right.$.), and a final extension of $64^{\circ} \mathrm{C} / 5 \mathrm{~min}$. The PCR amplicons of all genes, for each isolate, were pooled and purified using an Agencourt AMPure XP purification system and quantified using a Qubit double-stranded DNA (dsDNA) HS assay kit (Thermo Fisher Scientific). Sequencing was conducted on Illumina ${ }^{\circ}$ MiSeq systems. Initially, libraries were prepared using a Nextera XT kit, according to the manufacturer's protocol (Illumina Nextera ${ }^{\circ}$ XT DNA Sample Preparation Guide, 2012). Following PCR cleanup, libraries were quantified using a Qubit dsDNA BR kit, and evaluated for fragment size using an Agilent High Sensitivity DNA Kit, designed for the 2100 Bioanalyzer (Agilent Technologies, Santa Clara, CA, USA). Each library was normalized for sequencing to $10 \mathrm{pM}$, according to the manufacturer's protocol, and following Illumina's (Illumina ${ }^{\circ}$, SanDiego, CA, USA) directions for cluster optimization (Illumina Nextera ${ }^{\circ}$ Library Validation and Cluster Density Optimization, 2013). Sequencing reactions were carried out using a MiSeqReagent Kit V2, for 50 cycles (MiSeq, Illumina). SNPs in all genes were called using the reference sequence of the $P$. falciparum 3D7 clone, version 3 (PlasmoDB, PF3D7 v3).

\section{Data analysis}

All samples that contained gametocyte transcripts, as detected by qRT-PCR, were assessed for association between gametocyte carriage and total parasitemia. A Mann-Whitney U test was used to examine the difference in density between early- and late-stage gametocytes. Spearman's rank correlation was used to test for association between total parasite density (18S rRNA copy number) and the density of both latestage gametocytes (Pfs25 copy number) and earlystage gametocytes (Pfpeg4 copy number). Microsatellite data was filtered to retain only minor alleles having a peak height of $>33 \%$ of the predominant allele, if more than one allele was present at a given locus. Genetic diversity metrics were primarily calculated using GenAlEx v6.5 [24]. Expected heterozygosity was calculated using the formula for 'unbiased heterozygosity' also termed haploid genetic diversity, $H e=[n /(n-1)]\left[1-\Sigma p^{2}\right]$, where $n$ is the number of isolates and $p$ is the frequency of each allele at a given locus [25]. Population differentiation was assessed using Wright's FST index in Fstat version 2.9.3.2. Two estimators of $F S T\left(G^{\prime} S T\right.$ and $\left.\theta\right)$ [26, 27] were used to estimate genetic differentiation between imported parasites from the Indian subcontinent and imported parasites from sub-Saharan Africa. Multiplicity of infection (MOI), defined as the presence of multiple genotypes per infection, was assessed through the detection of multiple alleles at a given locus. To avoid the over estimation of low-abundance alleles, only minor alleles having a peak height of > $33 \%$ of the corresponding predominant alleles were accepted. The proportion of samples with more than one allele across ten loci was used to represent MOI. The maximum number of alleles across the ten loci was used as an index for minimum number of clones per infection (MNC). The overall mean of the index value for each sample was then calculated. 


\section{Results}

Demographic characteristics of imported malaria cases in Qatar

Among the 583 patients (all expatriates) tested for malaria between January 2013 and October 2016 in Hamad General Hospital and Al-Khor Hospital, Doha, Qatar, 448 (76.8\%) tested positive for malaria: 318 for $P$. vivax (70.9\%), 118 for P. falciparum (26.3\%) and 12 (2.7\%) for $P$. vivax / P. falciparum coinfection (Table 1) (Supplementary Table 1).

The primary origin of those presenting with $P$. vivax was the Indian subcontinent: India $(46.0 \%, n=146)$, Pakistan (32.1\%, $n=102)$ and Nepal (3.8\%, $n=12)$. A smaller proportion of $P$. vivax cases were from subSaharan Africa $(16 \%, n=53)$ (Table 1). Unlike $P$. vivax, the primary origin of $P$. falciparum infection was Africa: East Africa (76.1\%, $n=67)$, West and Central Africa
(23.9\%, $n=21$ ), followed by the Indian subcontinent $(20.3 \%, n=24)$ and other regions $(5.1 \%, n=6)$ (Table 1$)$.

\section{Parasitaemia and gametocytaemia among imported malaria cases}

Ninety of the $118 \quad P$. falciparum infections were examined for (1) total parasite density (qPCR), (2) total gametocyte density (qRT-PCR), (3) diversity within 10 microsatellites, and (4) four genes linked to drug resistance. The total $P$. falciparum density among imported cases varied widely, ranging between 32 and 9,218,498 parasites/ml of blood, with a median of 82,783 parasites/ ml. The median parasite density among imported cases from the Indian subcontinent $(99,572$ parasites/ml) was not significantly different from the parasite density among imported cases from Africa $(88,504$ parasites/ml) $(P=0.394)$.

Table 1 Origin of imported malaria cases in Qatar between 2013 and 2016. The percentage values in brackets represent the proportion of one species originating from the country listed. The information on the originating country of the expatriates was obtained in response to the questionnaire and may not reflect all countries through which the individual travelled prior to arrival in

\begin{tabular}{|c|c|c|c|c|}
\hline Country & Origin & P. vivax (\%) & P. falciparum (\%) & P. vivax $+P$. falciparum \\
\hline \multirow[t]{4}{*}{ The Indian Subcontinent } & India & $148(46.5 \%)$ & $18(15.3 \%)$ & 2 \\
\hline & Pakistan & $104(32.7 \%)$ & $4(3.4 \%)$ & 0 \\
\hline & Sri Lanka & 0 & $1(0.8 \%)$ & 0 \\
\hline & Nepal & $12(3.8 \%)$ & $1(0.8 \%)$ & 0 \\
\hline \multirow[t]{14}{*}{ Africa } & Mauritania & $1(0.3 \%)$ & 0 & 0 \\
\hline & Sudan & $34(10.7 \%)$ & $36(30.5 \%)$ & 4 \\
\hline & Kenya & $3(0.9 \%)$ & $16(13.6 \%)$ & 3 \\
\hline & Nigeria & $3(0.9 \%)$ & $11(9.3 \%)$ & 2 \\
\hline & Eritrea & $5(1.6 \%)$ & $10(8.5 \%)$ & 1 \\
\hline & Ethiopia & $5(1.6 \%)$ & $3(2.5 \%)$ & 0 \\
\hline & Ghana & $1(0.3 \%)$ & $3(2.5 \%)$ & 0 \\
\hline & Rwanda & 0 & $2(1.7 \%)$ & 0 \\
\hline & Cameroon & 0 & $2(1.7 \%)$ & 0 \\
\hline & Tanzania & $1(0.3 \%)$ & $1(0.8 \%)$ & 0 \\
\hline & Djibouti & 0 & $1(0.8 \%)$ & 0 \\
\hline & Democratic Republic of Congo & 0 & $1(0.8 \%)$ & 0 \\
\hline & Republic of Ivory Coast & 0 & $1(0.8 \%)$ & 0 \\
\hline & Chad & 0 & $1(0.8 \%)$ & 0 \\
\hline \multirow[t]{7}{*}{ Others $^{a}$} & Romania & 0 & $1(0.8 \%)$ & 0 \\
\hline & USA & 0 & $1(0.8 \%)$ & 0 \\
\hline & Syria & 0 & $1(0.8 \%)$ & 0 \\
\hline & Qatar & 0 & $1(0.8 \%)$ & 0 \\
\hline & Saudi Arabia & 0 & $1(0.8 \%)$ & 0 \\
\hline & Spain & 0 & $1(0.8 \%)$ & 0 \\
\hline & Canada & $1(0.3 \%)$ & 0 & 0 \\
\hline Total & & 318 & 118 & 12 \\
\hline
\end{tabular}


Seventy-three $P$. falciparum isolates were successfully examined by qRT-PCR to detect and quantify transcripts of genes expressed in early- (Pfpeg4) and late-stage gametocytes (Pfs25). The prevalence of all gametocytes was $74 \%(n=54)$, with $9.6 \%(n=7)$ of subjects possessing only early-stage gametocytes, 37\% $(n=27)$ possessing only late-stage gametocytes, and $27.4 \%(n=20)$ possessing a mixture of both stages. Early- stage gametocytes were found at a density ranging between 14 and 3781/ $\mathrm{ml}$ blood, with a median of $1011 / \mathrm{ml}$. Late-stage gametocytes were found at a density of ranging between 16 and $15,289 / \mathrm{ml}$ blood, with a median of $136 / \mathrm{ml}$ blood). There was a significant difference in the density of earlyand late-stage gametocyte densities (Mann-Whitney U test, $P=0.003)$. There was no correlation between total parasitaemia (18S rRNA copy number) and either late gametocyte density ( $P f_{s} 25$ copy number) $\left(\mathrm{r}_{\mathrm{s}}=0.008, P=\right.$ $0.946)$ or early gametocyte density (Pfpeg4 copy number) $\left(\mathrm{r}_{\mathrm{S}}=0.031, P=0.835\right)$ (Fig. 1).

\section{Genetic diversity and the structure of imported $P$. falciparum \\ Microsatellite polymorphism}

All 10 microsatellites examined were highly polymorphic for $P$. falciparum isolates originating in sub-Saharan Africa and the Indian subcontinent (Table 2). The number of alleles per locus was greater among African isolates, ranging from 5 ( $P f g 377)$ to 18 (poly $\alpha$ ), compared to isolates from the Indian subcontinent, that ranged from 3 (2490) to 7 (TA1 and PfPK2) (Table 2; Supplementary Table 2). Nevertheless, allelic diversity (defined as the mean expected heterozygosity $(\mathrm{He})$ across 10 microsatellite loci) was not significantly different among parasites from the Indian subcontinent (mean $\mathrm{He}=0.78$ ) compared to those from sub-Saharan Africa (mean $\mathrm{He}=$ 0.76) $(P=0.333)$.

Multi-locus haplotypes were constructed using predominant alleles at all examined loci. All 90 isolates differed from each other by at least one examined locus, with the exception of two isolates from Sudan.

\section{Multiplicity of infection (MOI)}

Seventy-six (84.4\%) of the 90 imported P. falciparum isolates with complete available data possessed multiple genotypes. The minimum number of genotypes per infected person (the mean maximum number of alleles observed at all loci) was slightly lower in sub-Saharan Africa (2.16 genotypes) than the Indian subcontinent (2.38 genotypes) $(\alpha<0.05)(P=0.667)$.

\section{Genetic differentiation}

Alleles of most $P$. falciparum microsatellites were distributed widely among imported malaria cases from both sub-Saharan Africa $(n=77)$ and the Indian subcontinent $(n=13)$. A relatively large number of private alleles (alleles detected only in one geographic region) were seen in Africa $(n=50)$ compared to the Indian subcontinent $(n=5)$. This may reflect the smaller sample size of subjects with origins in the Indian continent. Despite this trend, no evidence of genetic differentiation was observed between imported $P$. falciparum from sub-Saharan Africa and that imported from the Indian subcontinent $\left(F_{S T}=0.055\right)$. The genetic relatedness between $P$. falciparum
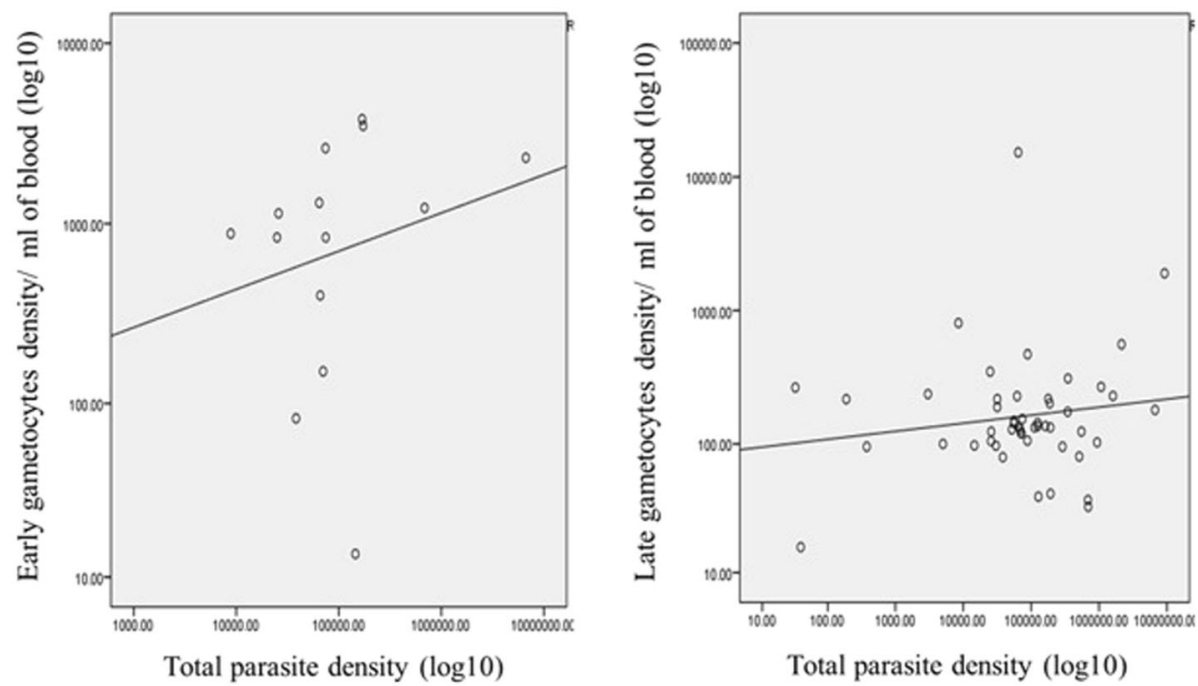

Fig. 1 Correlation between total parasite density with both early gametocyte and late gametocyte density. a log total parasitaemia ( $X$ axis) and log early gametocyte density (Y axis), the fit line in scatter plot shows a weak/non-significant correlation coefficient $(r=0.031, p=0.835)$. b log total parasitaemia ( $X$ axis) and log late gametocyte density ( $Y$ axis), the fit line in scatter plot shows a weak/non-significant correlation coefficient $(r=0.008, p=0.946)$ 
Table 2 Number of alleles and expected heterozygosity $(\mathrm{He})$ at ten microsatellite loci within imported Plasmodium falciparum from the Indian Subcontinent and Africa

\begin{tabular}{|c|c|c|c|c|c|c|c|c|c|c|c|}
\hline Origin of isolates & & 2490 & Pfg377 & polya & TA109 & TA81 & ARA2 & PfPK2 & TA1 & TA60 & TA87 \\
\hline \multirow[t]{2}{*}{ The Indian Subcontinent $(n=13)$} & Alleles & 3 & 4 & 6 & 5 & 5 & 5 & 7 & 7 & 6 & 6 \\
\hline & $\mathrm{He}$ & 0.67 & 0.68 & 0.87 & 0.81 & 0.74 & 0.71 & 0.91 & 0.87 & 0.72 & 0.86 \\
\hline \multirow[t]{2}{*}{ Africa $(n=77)$} & Alleles & 7 & 5 & 18 & 10 & 10 & 11 & 9 & 13 & 6 & 10 \\
\hline & $\mathrm{He}$ & 0.48 & 0.58 & 0.93 & 0.81 & 0.76 & 0.81 & 0.78 & 0.85 & 0.76 & 0.83 \\
\hline
\end{tabular}

populations was assessed using PCoA analysis (Fig. 2), which showed overlap between two populations. Analysis of molecular variance (AMOVA) within P. falciparum isolates imported from the Indian subcontinent and Africa revealed that the majority of genetic variation occurred between individuals within populations (95\%), compared to differences between populations $(P<0.001)$.

\section{Distribution of drug resistance mutations}

Seventy imported P. falciparum isolates were examined by amplicon sequencing for four putative drug resistance genes, PfK13, Pfmdr1, Pfcrt and Pfmrp1 (Table 3). With the exception of PfK13, there was no difference in the prevalence of wild-type alleles among parasites originating from sub-Saharan Africa versus the Indian subcontinent. There was, however, a significantly higher prevalence of mutant PfK 13 haplotypes among parasites from Africa than the Indian subcontinent $(P=0.0036)$. One nonsynonymous mutation in PfK13 (K189T) was observed at a prevalence of $36 \%$ among parasites originating from Sudan $(n=36)$, similar to reported findings from other African countries [28]. Ten additional nonsynonymous SNPs within PfK13 were identified at prevalences ranging from 1 to $3 \%$ : K108E (2\%), L119L (1\%),
H136N (1\%), T149S (2\%), K189N (2\%), N217H (1\%), R255K (3\%), I354V (1\%), E433D (1\%) and G453A (1\%) (Table 3; Supplementary Table 3).

PfK13 variants including the substitutions C580Y, Y493H, R539T and M579I, previously shown to be associated with slow artemisinin clearance of $P$. falciparum $[29,30]$, were not detected among P. falciparum isolates in this study. However, mutations in the gene Pfmdr1, also associated with reduced ACT susceptibility in some studies [31], as well as in resistance to other antimalarial drugs such as chloroquine [32], were found in the imported parasites. The Pfmdr1 polymorphisms N86Y and Y184F were prevalent among imported $P$. falciparum isolates (33 and $77 \%$, respectively). In addition, six rare nonsynonymous SNPs were detected (see Table 3). The $\mathrm{N}_{86} \mathbf{F}_{184} \mathrm{D}_{1246}$ and $\mathbf{Y}_{\mathbf{8 6}} \mathbf{F}_{184} \mathrm{D}_{1246}$ haplotypes, associated with artemether-lumefantrine (AL) tolerance [33] and chloroquine/amodiaquine (CQ/AQ) treatment failure, were reported among imported $P$. falciparum cases, at 43 and 33\%, respectively.

Notably, while the Pfcrt K76T substitution associated with $\mathrm{CQR}$ was found at a relatively low frequency $(n=$ 70, 6\%), other SNPs implicated in CQR were observed at higher prevalence: A220S (53\%), Q271E (49\%), N326D/S (36\%), I356L (6\%) and R371I (47\%). Overall, the CQ

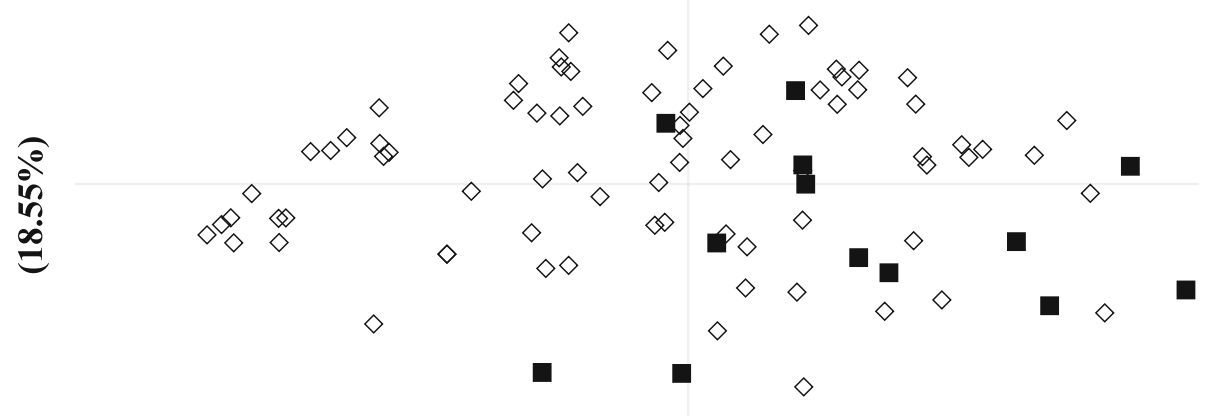

$(25.16 \%)$

$\diamond$ Africa $\quad$ The Indian subcontinent

Fig. 2 Principal Co-ordinates Analysis (PCOA) of P. falciparum populations from two regions (the Indian Subcontinent [black square] and Africa [transparent rectangular]). Values within parenthesis after the coordinate number are the percentage of variation explained by the coordinate 
Table 3 Haplotypes of drug resistance genes, that exist at a prevalence of more than 5\%, among imported P. falciparum cases in Qatar. Haplotypes are shown as amino acids (wild-type in normal case, substitutions in bold underlined)

\begin{tabular}{|c|c|c|c|c|c|c|}
\hline Locus & Genotype & Haplotype & Prevalence & the Indian subcontinent $(n=7)$ & Africa $(n=63)$ & $P$ value \\
\hline \multirow[t]{4}{*}{ Pfcrt } & Wild type & $\mathrm{C}_{72} \mathrm{~K}_{76} \mathrm{~A}_{220} \mathrm{Q}_{271} \mathrm{~N}_{326} \mathrm{I}_{356} \mathrm{R}_{371}$ & $44 \%$ & $1(14 \%)$ & $30(48 \%)$ & 0.1233 \\
\hline & Mutant & $C_{72} K_{76} \underline{\mathbf{S}}_{220} \underline{\mathbf{E}}_{271} \mathrm{~N}_{326} \mathrm{I}_{356} \mathrm{R}_{371}$ & $13 \%$ & $6(85 \%)$ & $33(52 \%)$ & \\
\hline & Mutant & $C / S_{72} \underline{\mathbf{T}}_{76} \underline{\mathbf{S}}_{220} \underline{\mathbf{E}}_{271} \mathrm{~N}_{326} \mathrm{I}_{356} \mathrm{R}_{371}$ & $5 \%$ & & & \\
\hline & Mutant & $\mathrm{C}_{72} \mathrm{~K}_{76} \underline{\mathbf{S}}_{220} \underline{\mathbf{E}}_{271} \underline{\mathbf{S}}_{326} \mathrm{I}_{356} \mathrm{R}_{371}$ & $29 \%$ & & & \\
\hline \multirow[t]{3}{*}{ Pfmdr1 } & Wild type & $N_{86} F_{184} F_{938} G_{968} D_{1246}$ & $39 \%$ & $4(57 \%)$ & 23(37\%) & 0.4118 \\
\hline & Mutant & $N_{86} \underline{\mathbf{Y}}_{184} \mathrm{~F}_{938} \underline{G}_{968} \mathrm{D}_{1246}$ & $10 \%$ & $3(43 \%)$ & $43(68 \%)$ & \\
\hline & Mutant & $\underline{\mathbf{Y}}_{86} \mathrm{~F}_{184} \mathrm{~F}_{938} \mathrm{G}_{968} \mathrm{D}_{1246}$ & $30 \%$ & & & \\
\hline \multirow[t]{2}{*}{ PfK13 } & Wild type & $\mathrm{H}_{136} \mathrm{~T}_{149} \mathrm{~K}_{189} \mathrm{~N}_{217 \mathrm{R} 255} \mathrm{E}_{433} \mathrm{G}_{453}$ & $47 \%$ & $7(100 \%)$ & $26(41 \%)$ & 0.0036 \\
\hline & Mutant & $\mathrm{H}_{136 \mathrm{~T} 149} \underline{\mathbf{T}_{\mathbf{1 8 9}}} \mathrm{N}_{217} \mathrm{R}_{255} \mathrm{E}_{433} \mathrm{G}_{453}$ & $34 \%$ & $0(0 \%)$ & $37(59 \%)$ & \\
\hline \multirow[t]{4}{*}{ Pfmrp1 } & Wild type & $\mathrm{H}_{191} \mathrm{~K}_{202} \mathrm{~S}_{437} \mathrm{I}_{876} \mathrm{~L}_{1342} \mathrm{~F}_{1390} \mathrm{~K}_{1466} \mathrm{D}_{1533}$ & $31 \%$ & $1(14 \%)$ & $21(33 \%)$ & 0.4201 \\
\hline & Mutant & $\mathrm{H}_{191} \mathrm{~K}_{202} \mathrm{~S}_{437} \underline{\mathbf{V}}_{876} \mathrm{~L}_{1342} \mathrm{~F}_{1390} \mathrm{~K}_{1466} \mathrm{D}_{1533}$ & $6 \%$ & $6(86 \%)$ & $42(67 \%)$ & \\
\hline & Mutant & $\mathrm{H}_{191} \mathrm{~K}_{202} \mathrm{~S}_{437} \underline{\mathbf{V}}_{876} \mathrm{~L}_{1342} \mathrm{~F}_{1390} \underline{\mathbf{R}}_{1466} \mathrm{D}_{1533}$ & $10 \%$ & & & \\
\hline & Mutant & $\underline{\mathbf{Y}}_{191} \mathrm{~K}_{202} \underline{\mathbf{A}}_{437} \underline{\mathbf{V}}_{876} \mathrm{~L}_{1342} \underline{\mathbf{I}}_{1390} \mathrm{~K}_{1466} \mathrm{D}_{1533}$ & $5 \%$ & & & \\
\hline
\end{tabular}

sensitive haplotype $\mathrm{C}_{72} \mathrm{~V}_{73} \mathrm{M}_{74} \mathrm{~N}_{75} \mathrm{~K}_{76}$ was common (94\%), while the CQ resistant haplotypes, $\mathbf{S}_{72} \mathrm{~V}_{73} \mathrm{M}_{74} \mathrm{~N}_{75} \mathbf{T}_{76}$ and $\mathrm{C}_{72} \mathrm{~V}_{73} \mathrm{M}_{74} \mathrm{~N}_{75} \mathbf{T}_{76}$, were detected in only one and three isolates, respectively.

Regarding Pfmrp1, eight variants were observed among imported P. falciparum specimens, ranging from a frequency of $46 \%$ for I876V to 3\% for D1533V (Table 3, Supplementary Table 3). The five most common variants [H191Y, S437A, I876V, F1390I, K1466R] detected among imported cases were all previously reported in the Indian subcontinent and Africa [34, 35], however, they existed at a relatively higher frequency in isolates from Africa compared to those from the Indian subcontinent (Supplementary Table 3). Pfmrp1 polymorphisms previously associated with decreased in vitro susceptibility to SP, artemisinin, mefloquine, and lumefantrine were common. The most frequent SNP, encoding I876V (46\%), was found to be under significant selection pressure following AL treatment [34].

\section{Discussion}

Sustainable interventions driven by global support have resulted in a noteworthy global malaria case reduction in the past three decades [5]. Twenty-one countries were identified by the WHO for the complete elimination of malaria by the year 2020 [36]. Drug resistance in Plasmodium species and insecticide resistance in malaria vectors, as well as human sociodemographic factors, have the potential to obstruct this worthy goal. Mass international human migration from malaria-endemic regions where a proportion of semi-immune residents sustain asymptomatic, low levels of parasitemia has been shown to be a risk factor for the reintroduction of local malaria transmission.
Asymptomatic $P$. falciparum infection can develop into clinical malaria in individuals up to 8 years after migration to a malaria-free country [37, 38]. Therefore, asymptomatic migrants with malaria parasite infections can act as a long-lasting reservoir for secondary local transmission in receptive malaria-free areas, where elimination has been accomplished $[3,39]$. This potential is evident in the high prevalence of gametocyte carriage seen among imported $P$. falciparum malaria cases in Qatar. Fifty-four of 73 imported P. falciparum isolates (74\%) examined by qRT-PCR [40] possessed gametocyte stages, with a large proportion (37\%) harboring both early-stage and late-stage gametocytes. This trend is indicative of ongoing gametocytogenesis from the asexual population present in the patient. Low-density gametocytes can readily infect Anopheles vectors, even at submicroscopic levels [41, 42]. Secondary transmission, arising from imported malaria cases, is often reported in GCC countries in areas where the Anopheles vector is present, and a favorable ecological habitat exists [3, 43]. The surge in Anopheles abundance in highly-seasonal transmission settings has been associated with an upsurge in gametocyte numbers in asymptomatic carriers [20]. This is in line with enhanced parasite infectivity in response to increased exposure to uninfected mosquitoes at the start of the transmission season, in areas with marked seasonal malaria [20, 44]. Although the resumption of endemic malaria transmission in GCC countries is unlikely given current models, the high rate of imported malaria can readily seed outbreaks, if vector control wanes [3].

The genetic diversity, measured as $H_{e}$, of $P$. falciparum imported into Qatar from sub-Saharan Africa (0.76) and the Indian subcontinent $(0.78)$, is similar to that reported 
locally in both sites of origin $[17,40]$, as well as within local transmission sites that still exist in Saudi Arabia (0.76) and Yemen (0.585) [45]. This pattern is also found in genotype multiplicity. These trends underscore the role of imported malaria in enriching Plasmodium genetic diversity, as well as in introducing drug resistance lineages in areas moving towards elimination, such as Saudi Arabia [46] and Oman [3]. Moreover, the combination of high genotype multiplicity and gametocyte carriage, as reported in the present study, increases the likelihood that imported malaria infections will generate novel genotypes, should transmission occur [47]. Thus, imported malaria cases to Qatar represent not only a risk for the ignition of local transmission, but also a risk of creating novel strains that can escape the effect of current drug regimens. Efforts to thwart the reintroduction of malaria in transmission-free areas of the GCC currently rely on effective case management using artemisinin-combination therapy. The present study revealed a relatively high prevalence of SNPs in four unlinked genes implicated in drug resistance, namely $P f c r t$, Pfmdr1, Pfmrp1 and PfK13.

With the exception of $P f K 13$, there was no difference in the distribution of drug resistance alleles between Plasmodium parasites introduced from the Indian subcontinent as compared to those from sub-Saharan Africa. The wild type allele of PfK 13 was found at high prevalence in $P$. falciparum imported from sub-Saharan Africa and the Indian subcontinent, and the variants C580Y, Y493H, R539T, and M579I, previously associated with slow artemisinin clearance $[28,30]$, were not detected.. Numerous low-frequency (1 to 3\%) SNPs in PfK13 in parasites from sub-Saharan Africa and the Indian subcontinent were observed(K108E, L119L, H136N, T149S, K189N, N217H, R255K, I354V, E433D, G453A), while one SNP, K189T, was observed at a conspicuously higher frequency $(36 \%)$ among parasites originating specifically from Sudan [28]. However, parasites carrying mutation K189T have previously been found to have a similar therapeutic response (parasite clearance half-life) to ACT to wild type parasites [28], and thus may not have an impact on the current ACT regimen in Qatar for uncomplicated and complicated $P$. falciparum infection [11].

The presence of SNPs or haplotypes linked to tolerance of artemisinin derivatives can however impact on current elimination strategies, potentially resulting in persistence of symptoms and an increased local parasite reservoir. We reported a high prevalence of the Pfmdr1$\mathrm{N}_{86} \mathbf{F}_{184} \mathrm{D}_{1246}$ haplotype (43\%), which is associated with reduced AL susceptibility [31]. The two most common variants of Pfmrp1, F1390I (79\%) and I876V (46\%), have been linked to a decreased susceptibility to artemisinin, mefloquine, and lumefantrine [36, 48]. These findings suggest that regular monitoring of the above SNPs, coupled with an appropriate, tailored clinical response, should be employed to combat the spread of P. falciparum parasites with potential AL tolerance. Studies in Saudi Arabia and Yemen have revealed a high frequency of drug resistance genotypes among locally-acquired $P$. falciparum infections, the source of which was linked statistically to sub-Saharan Africa and Indian subcontinent $[34,48]$.

A noteworthy observation from the present study was the divergence in the frequency of Pfcrt mutation K76T (11\%) compared to mutations A220S (54\%), Q271E (50\%), N326D/S (37\%), and R371I (48\%). Like K76T, the latter mutations have been associated with reduction in CQ transport activity and CQR [49]. The relatively low frequency of the K76T mutation may reflect the fitness cost of the variant, coupled with reduced exposure to CQ [50], while the other mutations may carry lower fitness costs and so be maintained in the population. Alternatively, the latter $P f c r t$ mutations may be under selective pressures from both CQ and other antimalarial drugs.

\section{Conclusions}

The present study expounds upon the threat that imported Plasmodium parasites represent for the reintroduction of malaria in receptive, transmission-free areas, such as Qatar. The high levels of genetic diversity found, as well as the high capacity of imported P. falciparum to produce gametocytes, highlights the threat of spread of drug resistance genotypes, should local transmission reoccur. There is an urgent need for molecular tools, such as the highly sensitive and high-throughput qPCR that can detect $>20$ parasites/ml blood [51], for the surveillance of imported malaria cases in Qatar and the GCC, to limit the risk of reintroduction of malaria.

\section{Supplementary information}

Supplementary information accompanies this paper at https://doi.org/10. 1186/s12879-020-05111-6.

\section{Additional file 1: Table S1. Demographic data of imported $P$.} falciparum malaria cases.

Additional file 2: Table S2. Allele size of 10 microsatellites among imported P. falciparum to Qatar.

Additional file 3: Table S3. Prevalence of wild-type and mutant alleles of drug resistance genes among imported P. falciparum to Qatar. Values in brackets are percentages.

\section{Abbreviations}

GCC: Gulf Cooperation Council; HMC: Hamad Medical Corporation; MOI: Multiplicity of infection; qRT-PCR: Quantitative Reverse TranscriptasePolymerase Chain Reaction; MNC: Minimum number of clones per infection; $\mathrm{H}_{e}$ : Expected heterozygosity; $\mathrm{F}_{\text {ST: }}$ Fixation index; PCOA: Principle coordinates analysis; AMOVA: Analysis of molecular variance; ACT: Artemisinin-based combination therapy; AL: Artemether-Lumefantrine; CQ: Chloroquine; 
AQ: Amodiaquine; CQR: Chloroquine Resistance; SP: Sulfadoxine pyrimethamine; WHO: World Health Organization

\section{Acknowledgements}

We would like to thank the medical and paramedical staff of HMC, Doha, Qatar, for assisting with sample collection. In addition, we thank all study respondents and their relatives for their participation. Lastly, we thank Fathia Ben Rached (KAUST) for her assistance constructing the Illumina library and for running the Miseq equipment to produce raw sequencing data.

\section{Authors' contributions}

HAB, AAS, LRC and AP conceived the study and designed the experiments. $A R, Z H, S A, A G$ and RN contributed to data collection and data analysis. All author(s) read and approved the final manuscript.

\section{Funding}

This publication was made possible by Sultan Qaboos University, Oman (Studentship for AR), and NPRP grant [NPRP 5-098 - 3 - 021] from the Qatar National Research Fund (a member of Qatar Foundation). The work was also funded through International Atomic Energy Agency (IAEA) grant OMA/6/ 006, and King Abdullah University of Science and Technology (KAUST) grant BAS/1/1020-01-01 (to AP).

The above funding bodies played no role in the design of the study,

collection, analysis, and interpretation of data, and in writing the manuscript.

\section{Availability of data and materials}

The datasets used in the current study are available from the corresponding author on reasonable request.

\section{Ethics approval and consent to participate}

Ethical clearance for the study was obtained from the Institutional Review Board of HMC and Weill Cornell Medicine-Qatar (Protocol no.14-00097). A signed consent was obtained from each participant before any interview or clinical examination was conducted.

\section{Consent for publication}

Not applicable.

\section{Competing interests}

The authors declare that they have no competing interests.

\section{Author details}

'Department of Biochemistry, College of Medicine and Health Sciences, Sultan Qaboos University, Muscat, Oman. ${ }^{2}$ Biological and Environmental Sciences and Engineering Division, King Abdulla University for Science and Technology (KAUST), Thuwal, Kingdom of Saudi Arabia. ${ }^{3}$ Institute of Biodiversity, Animal Health and Comparative Medicine, College of Medical, Veterinary and Life Sciences, University of Glasgow, Glasgow G12 8QQ, Scotland, UK. ${ }^{4}$ Research Centre for Zoonosis Control, Global Institution for Collaborative Research and Education (Gl-CoRE), Hokkaido University, N20 W10 Kita-ku, Sapporo, Japan. ${ }^{5}$ Nuffield Division of Clinical Laboratory Sciences (NDCLS), The John Radcliffe Hospital, University of Oxford, Headington, Oxford OX3 9DU, UK. ${ }^{6}$ Department of Microbiology and Immunology, Weill Cornell Medicine - Qatar, Cornell University, Qatar Foundation - Education City, Doha, Qatar. ${ }^{7}$ Institute of Immunology and Infection Research, School of Biological Sciences, University of Edinburgh, Edinburgh, UK

\section{Received: 6 February 2020 Accepted: 20 May 2020}

Published online: 15 June 2020

\section{References}

1. Snow RW, Amratia P, Zamani G, Mundia CW, Noor AM, Memish ZA, Al Zahrani MH, Al Jasari A, Fikri M, Atta H. The malaria transition on the Arabian peninsula: progress toward a malaria-free region between 19602010. Adv Parasitol. 2013;82:205-51

2. Soliman RH, Garcia-Aranda P, Elzagawy SM, Hussein BE-S, Mayah WW, Ramirez AM, Ta-Tang T-H, Rubio JM. Imported and autochthonous malaria in West Saudi Arabia: results from a reference hospital. Malar J. 2018:17(1): 286
3. Simon B, Sow F, Al Mukhaini SK, Al-Abri S, Ali OAM, Bonnot G, Bienvenu AL, Petersen $\mathrm{E}$, Picot $\mathrm{S}$. An outbreak of locally acquired Plasmodium vivax malaria among migrant workers in Oman. Parasite (Paris, France). 2017;24:25.

4. World Health Organization: Regional malaria action plan 2016-2020: towards a malaria-free Region. In.: World Health Organization. Regional Office for the Eastern Mediterranean; 2017.

5. World Health Organization. World malaria report 2016. Geneva: World Health Organization; 2017 p. 186.

6. Beljaev AE. The malaria situation in the WHO eastern Mediterranean region. Med Parazitol. 2000;2:12-5.

7. Al-Kuwari MG. Epidemiology of imported malaria in Qatar. J Travel Med. 2009;16(2):119-22.

8. Chaabna K, Cheema S, Mamtani R. Migrants, healthy worker effect, and mortality trends in the Gulf cooperation council countries. PLoS One. 2017; 12(6):e0179711.

9. Bansal D, Acharya A, Bharti PK, Abdelraheem MH, Elmalik A, Abosalah S, Khan FY, ElKhalifa M, Kaur H, Mohapatra PK. Distribution of mutations associated with antifolate and chloroquine resistance among imported Plasmodium vivax in the state of Qatar. Am J Tropical Med Hygiene. 2017; 97(6):1797-803.

10. Farag E, Bansal D, Chehab MAH, Al-Dahshan A, Bala M, Ganesan N, Al Abdulla YA, Al Thani M, Sultan AA, Al-Romaihi H: Epidemiology of Malaria in the State of Qatar. Mediterranean J Hematol Infectious Dis. 2008-2015;2018:10(1).

11. Khan FY, Lutof AK, Yassin MA, Khattab MA, Saleh M, Rezeq HY, Almaslamani M. Imported malaria in Qatar: a one year hospital-based study in 2005. Travel Med Infect Dis. 2009;7(2):111-7.

12. Tatem AJ, Smith DL. International population movements and regional Plasmodium falciparum malaria elimination strategies. Proc Natl Acad Sci. 2010;107(27):12222-7.

13. Abdelraheem MH, Bansal D, Idris MA, Mukhtar MM, Hamid MMA, Imam ZS, Getachew S, Sehgal R, Kaur H, Gadalla AH. Genetic diversity and transmissibility of imported Plasmodium vivax in Qatar and three countries of origin. Sci Rep. 2018;8(1):8870.

14. Silal SP, Little F, Barnes Kl, White LJ. Hitting a moving target: a model for malaria elimination in the presence of population movement. PLoS One 2015:10(12):e0144990.

15. Sturrock HJ, Roberts KW, Wegbreit J, Ohrt C, RD G: Tackling imported malaria: an elimination endgame. Am J Tropical Med Hygiene 2015, 93(1):139-144.

16. Snounou G. Genotyping of Plasmodium spp. Nested PCR. Methods Molecular Med. 2002;72:103-16.

17. Anderson, Haubold B, Williams JT, Estrada-Franco JG, Richardson L, Mollinedo R, Bockarie M, Mokili J, Mharakurwa S, French N, et al. Microsatellite markers reveal a spectrum of population structures in the malaria parasite Plasmodium falciparum. Mol Biol Evol. 2000;17(10):1467-82.

18. Anderson, Su XZ, Bockarie M, Lagog M, Day KP. Twelve microsatellite markers for characterization of Plasmodium falciparum from finger-prick blood samples. Parasitology. 1999:119.

19. Silvestrini F, Bozdech Z, Lanfrancotti A, Di Giulio E, Bultrini E, Picci L, Pizzi E, Alano P. Genome-wide identification of genes upregulated at the onset of gametocytogenesis in Plasmodium falciparum. Mol Biochem Parasitol. 2005; 143(1):100-10.

20. Gadalla AA, Schneider P, Churcher TS, Nassir E, Abdel-Muhsin AA, RanfordCartwright LC, Reece SE, Babiker HA. Associations between season and gametocyte dynamics in chronic Plasmodium falciparum infections. PLoS One. 2016:11(11):e0166699.

21. Hermsen CC, Telgt DS, Linders EH, Van De Locht LA, Eling WM, Mensink EJ, Sauerwein RW. Detection of Plasmodium falciparum malaria parasites in vivo by real-time quantitative PCR. Mol Biochem Parasitol. 2001;118(2):247-51.

22. Schneider, Reece SE, van Schaijk BC, Bousema T, Lanke KH, Meaden CS, Gadalla A, Ranford-Cartwright LC, Babiker HA. Quantification of female and male Plasmodium falciparum gametocytes by reverse transcriptase quantitative PCR. Mol Biochem Parasitol. 2015:199(1-2):29-33.

23. Rao PN, Uplekar S, Kayal S, Mallick PK, Bandyopadhyay N, Kale S, Singh OP, Mohanty A, Mohanty S, Wassmer SC. A method for amplicon deep sequencing of drug resistance genes in Plasmodium falciparum clinical isolates from India. J Clin Microbiol. 2016:54(6):1500-11.

24. Peakall R, Smouse PE. GenAlEx 6.5: genetic analysis in excel. Population genetic software for teaching and research —an update. Bioinformatics. 2012;28(19):2537-9.

25. Anon A. The evaluation of forensic DNA evidence. Proc Natl Acad Sci. 1996. 94(11):5498-500. 
26. Cockerham CC, Weir BS. Covariances of relatives stemming from a population undergoing mixed self and random mating. Biometrics. 1984; 40(1):157-64.

27. Nei M. Molecular evolutionary genetics. New York: Columbia University Press; 1987.

28. Andrianaranjaka V, Ashley E, Bethell D, Björkman A, Bonnington C, Cooper R, Dhorda M, Dondorp A, Erhart A, Fairhurst R: Association of mutations in the Plasmodium falciparum Kelch13 gene (Pf3D7_1343700) with parasite clearance rates after artemisinin-based treatments-a WWARN individual patient data meta-analysis. BMC Med 2019, 17(1):1-20.

29. Ariey F, Witkowski B, Amaratunga C, Beghain J, Langlois A-C, Khim N, Kim S, Duru V, Bouchier C, Ma L, et al. A molecular marker of artemisinin-resistant Plasmodium falciparum malaria. Nature. 2014;505(7481):50-5.

30. Lu F, Culleton R, Zhang M, Ramaprasad A, von Seidlein L, Zhou H, Zhu G, Tang J, Liu Y, Wang W. Emergence of indigenous artemisinin-resistant Plasmodium falciparum in Africa. N Engl J Med. 2017;376(10):991-3.

31. Ishengoma DS, Mandara Cl, Francis F, Talundzic E, Lucchi NW, Ngasala B, Kabanywanyi AM, Mahende MK, Kamugisha E, Kavishe RA. Efficacy and safety of artemether-lumefantrine for the treatment of uncomplicated malaria and prevalence of Pfk13 and Pfmdr 1 polymorphisms after a decade of using artemisinin-based combination therapy in mainland Tanzania. Malar J. 2019;18(1):88.

32. Babiker HA, Pringle SJ, Abdel-Muhsin A, Mackinnon M, Hunt P, Walliker D. High-level Chloroquine resistance in Sudanese isolates of Plasmodium falciparum is associated with mutations in the Chloroquine resistance transporter gene Pfcrt and the multidrug resistance gene Pfmdr1. J Infect Dis. 2001;183(10):1535-8.

33. Nzila A, Okombo J, Ohuma E, Al-Thukair A. Update on the in vivo tolerance and in vitro reduced susceptibility to the antimalarial lumefantrine. J Antimicrob Chemother. 2012;67(10):2309-15.

34. Dahlström S, Ferreira PE, Veiga MI, Sedighi N, Wiklund L, Mårtensson A, Färnert A, Sisowath C, Osório L, Darban H. Plasmodium falciparum multidrug resistance protein 1 and artemisinin-based combination therapy in Africa. J Infect Dis. 2009;200(9):1456-64.

35. Gupta P, Singh R, Khan H, Raza A, Yadavendu V, Bhatt R, Singh V. Genetic profiling of the Plasmodium falciparum population using antigenic molecular markers. Sci World J. 2014;2014.

36. Dhiman S. Correction to: are malaria elimination efforts on right track? An analysis of gains achieved and challenges ahead. Infect Dis Poverty. 2019; 8(1):19.

37. Jimenez BC, Cuadros-Tito P, Ruiz-Giardin JM, Rojo-Marcos G, CuadrosGonzalez J, Canalejo E, Cabello N, San Martin JV, Barrios AM, Hinojosa J, et al. Imported malaria in pregnancy in Madrid. Malar J. 2012;11:112.

38. Wångdahl A, Wyss K, Saduddin D, Bottai M, Ydring E, Vikerfors T, Färnert A Severity of Plasmodium falciparum and non-falciparum malaria in travelers and migrants: a nationwide observational study over two decades in Sweden. J Infect Dis. 2019.

39. Spanakos G, Alifrangis M, Schousboe ML, Patsoula E, Tegos N, Hansson HH, Bygbjerg IC, Vakalis NC, Tseroni M, Kremastinou J. Genotyping Plasmodium vivax isolates from the 2011 outbreak in Greece. Malar J. 2013;12(1):463.

40. Mobegi VA, Loua KM, Ahouidi AD, Satoguina J, Nwakanma DC, AmambuaNgwa A, Conway DJ. Population genetic structure of Plasmodium falciparum across a region of diverse endemicity in West Africa. Malar J. 2012;11(1):223.

41. Nwakanma, Kheir A, Sowa M, Dunyo S, Jawara M, Pinder M, Milligan P Walliker D, Babiker HA. High gametocyte complexity and mosquito infectivity of Plasmodium falciparum in the Gambia. Int J Parasitol. 2008; 38(2):219-27.

42. Ouédraogo AL, Roeffen W, Luty AJF, de Vlas SJ, Nebie I, Ilboudo-Sanogo E, Cuzin-Ouattara N, Teleen K, Tiono AB, Sirima SB, et al. Naturally acquired immune responses to Plasmodium falciparum sexual stage antigens Pfs48/ 45 and Pfs230 in an area of seasonal transmission. Infect Immun. 2011; 79(12):4957-64.

43. Ranjbar M, Shoghli A, Kolifarhood G, Tabatabaei SM, Amlashi M, Mohammadi M. Predicting factors for malaria re-introduction: an applied model in an elimination setting to prevent malaria outbreaks. Malar J. 2016;15:138.

44. Paul R, Diallo M, Brey P. Mosquitoes and transmission of malaria parasites not just vectors. Malar J. 2004;3(1):39.

45. Al-Hamidhi S, Mahdy MA, Idris MA, Bin Dajem SM, Al-Sheikh AA, Al-Qahtani A, Al-Hashami Z, Al-Farsi H, Al-Mekhlafi AM, Saif-Ali R, et al. The prospect of malaria elimination in the Arabian peninsula: a population genetic approach. Infection Genetics Evol. 2014;27:25-31.

46. El Hassan IM, Sahly A, Alzahrani MH, Alhakeem RF, Alhelal M, Alhogail A, Alsheikh AA, Assiri AM, ElGamri TB, Faragalla IA, et al. Progress toward malaria elimination in Jazan Province, Kingdom of Saudi Arabia: 2000-2014. Malar J. 2015;14:444

47. Hill WG, Babiker HA, Ranford-Cartwright LC, Walliker D. Estimation of inbreeding coefficients from genotypic data on multiple alleles, and application to estimation of clonality in malaria parasites. Genet Res. 1995; 65(1):53-61.

48. Veiga Ml, Ferreira PE, Jörnhagen L, Malmberg M, Kone A, Schmidt BA, Petzold M, Björkman A, Nosten F, Gil JP. Novel polymorphisms in Plasmodium falciparum $A B C$ transporter genes are associated with major ACT antimalarial drug resistance. PLoS One. 2011;6(5):e20212.

49. Summers RL, Dave A, Dolstra TJ, Bellanca S, Marchetti RV, Nash MN, Richards SN, Goh V, Schenk RL, WD S: Diverse mutational pathways converge on saturable chloroquine transport via the malaria parasite's chloroquine resistance transporter. Proc Natl Acad Sci 2014, 111(17):1759-1767.

50. Babiker HA, Hastings IM, Swedberg G. Impaired fitness of drug-resistant malaria parasites: evidence and implication on drug-deployment policies. Expert Rev Anti-Infect Ther. 2009;7(5):581-93.

51. Imwong M, Hanchana S, Malleret B, Rénia L, Day NP, Dondorp A, Nosten F, Snounou G, White NJ. High-throughput ultrasensitive molecular techniques for quantifying low-density malaria parasitemias. J Clin Microbiol. 2014;52(9): 3303-9.

\section{Publisher's Note}

Springer Nature remains neutral with regard to jurisdictional claims in published maps and institutional affiliations.

\section{Ready to submit your research? Choose BMC and benefit from:}

- fast, convenient online submission

- thorough peer review by experienced researchers in your field

- rapid publication on acceptance

- support for research data, including large and complex data types

- gold Open Access which fosters wider collaboration and increased citations

- maximum visibility for your research: over $100 \mathrm{M}$ website views per year

At BMC, research is always in progress.

Learn more biomedcentral.com/submissions 